\title{
Total kalça artroplastisi femoral komponent uygulama teknikleri
}

\section{Femoral component implanting techniques in total hip arthroplasty}

\author{
Mustafa Çeliktaş, Emre Toğrul \\ Özel Ortopedia Hastanesi, Adana
}

\begin{abstract}
Illk yapılan total kalça protezi uygulamalarının hepsinde femoral komponent çimento ile tespit edilmekteydi. 60 yaşın üzerindeki hastalarda bu uygulama işe yararken, daha genç ve aktif hastalarda sıklıkla kemik stoku kaybı ve implantta gevşemeler görüldü. Bunun üzerine, bir yandan çimentosuz tespitler, diğer yandan da çimentolama teknikleri geliştirilmeye başlandı. Kalça artroplastisinde çimentolu veya çimentosuz femoral stem kullanımı birçok faktöre bağlıdır. Hastanın yaşı, proksimal femoral geometri, hastanın kemik kalitesi bunlar arasında sayılabilir. Ayrıca her yöntemin kendine ait üzerinde düşünülmesi gereken avantaj ve dezavantajları vardır. Çimentosuz stemlerde stres kalkanı oluşumu, uyluk ağrısı, periprostetik kırık, çimentolu stemlerde çimento özellikleri, uygulama zamanlaması, uygulama teknikleri, her iki yöntemde de kullanılan metalin yüzey ve sertlik özellikleri, kaplama şekli, güncelliğini yitirmeyen konulardır. Günümüzde, genç hastalarda çimentosuz tespit, 60 yaşın üzerindeki hastalarda ise çimentolu femoral tespit daha fazla kullanılmaktadır. Hangi yöntem kullanılırsa kullanılsın aksamanın giderilmesi ve yardımcı yürüme cihazlarına ihtiyacın azaltılması gereklidir. Bunun için kalça çevresi yumuşak doku dengesi sağlanmalıdır. Femur başı rotasyon merkezi, femoral ofset uygun olarak oluşturulmalı, bacak uzunluğu eşitlenmeli ve abduktor mekanizma korunmalıdır. Ameliyat öncesi yapılan şablonlama, uygun implantların hazırlanması, istenilen anatominin planlanabilmesi için gereklidir.
\end{abstract}

Anahtar sözcükler: total kalça replasmanı; femur başı protezi; kemik çimentosu
The first attempts for implanting femoral component in total hip arthroplasties were cemented. It was usually a successful treatment for patients over 60 years of age, but for younger and more active patients implant loosening and bone reserve deficits were quite frequent. Therefore cementless implantation methods were developed while on the other hand manual cementing techniques improved. The preference of cementless or cemented implantation in hip arthroplasties depends on many factors such as patient age, proksimal femoral shape, and bone quality of femur. Besides, each method has numerous of advantages and disadvantages which must be considered deliberately. Stress shielding, thigh pain, periprostetic fracture in cementless systems, cement characteristics, timing and techniques for cemented systems and moreover, implant stiffness and stem surface quality for both systems are still contemporary issues. Nowadays cementless prosthesis are used for younger and daily active patients; on the other hand, cemented prosthesis, are preferred for patients over 60 years of age. Limping and necessity of walking aids need to be reduced, no matter which method is used For this issue, soft tissue balance must be provided pricipally. Center of femoral rotation, femoral offset must be appropriate and leg length must be equalized, and abductor mechanism must be preserved. Preoperative templating is necessary to prepare the proper implants in theatre and be able to plan the desired anatomy.

Key words: total hip replacement; femoral head prosthesis; bone cements
K alça ekleminde ortaya çıkan ileri derecede artritik değişiklikler, hastanın yaşam kalitesini oldukça fazla düşürürler. Total kalça protezi ise bu hastaların ağrısını geçiren ve kalça fonksiyonlarını geri kazandıran etkili bir yöntemdir. Bu yüzden total kalça protezi tüm medikal tedaviler içinde uygun maliyetli ve maliyet tasarrufu sağlayan yöntemler içerisinde anılır. ${ }^{[1,2]}$
Illk total kalça protezi uygulamalarının hepsinde femoral komponent çimento ile tespit edilmekteydi. 60 yaşın üzerindeki hastalarda bu uygulama işe yararken daha genç ve aktif hastalarda ise kemik stoku kaybı ve implantta gevşemeler sıkça görüldü. "Çimento hastalığı" adı verilen bu durumun çimentodan kaynaklandığı ortaya çıkınca implantı doğrudan kemiğe tespit etme yöntemleri araştırıldı.

- İletişim adresi: Dr. Mustafa Çeliktaş, Özel Ortopedia Hastanesi, Döşeme m. Cumhuriyet cad. No: 64, Seyhan, Adana

Tel: 0532 - 7427255 Faks: 0322 -4368110 e-posta: mstfceliktas@yahoo.com

- Geliștarihi: 7 Haziran 2013 Kabul tarihi: 11 Temmuz 2013 
Böylece 1970'lerin başında çimentosuz tespit ortaya çıktı. [3]

\section{ÇIMENTOSUZ FEMORAL KOMPONENT}

Genel olarak çimentosuz femoral komponentler üç farklı şekilde tasarlanmıştır. Bunlar konik incelen (tapered), anatomik ve silindirik şekildedir. Bu seçenekler arasındaki başlıca farklar komponent şekli, metalürjisi, baş-boyun tasarımı ve kemikle entegre olma şekli (üzerine büyüme, içine büyüme) olarak sıralanabilir.

Birçok cerrah için proksimal femoral medullar kanaIın şekli çimentosuz implant uygulaması için önemlidir. Genel olarak hastaların \%85'inde şampanya kadehi ve huni biçiminde diye adlandırabileceğimiz Dorr A ve B femoral morfoloji bulunmaktadır (Şekil 1). ${ }^{[4]}$ Bu hastalar çimentosuz tespit için çok uygun olmakla beraber silindirik olarak tanımlayabileceğimiz Dorr C morfolojilerde de çimentosuz sistemlerle yüksek başarı oranı bildiren çalışmalar vardır. ${ }^{[5,6]}$

Çimentosuz femoral stemlerin kullanımı biyolojik olarak inert güçlü metal alaşımların keşfinden sonra mümkün olmuştur. İlk kullanılan çimentosuz sistemlerde tespiti güçlendirici herhangi bir içe büyümeyi (ingrowth) sağlayan yüzey yoktu ve tespitin kalitesi sadece sıkıştırmaya bağlıydı. Ayrıca protezin ölçü çeşitliliği (size) de oldukça kısıtlıydı. Böylece uyluk ağrısı ve erken gevşeme sıkça görülmekteydi. Daha sonra tespiti güçlendirmek için poroz kaplamalı protez yüzeyleri kullanılmaya başlandı. Protez boyut çeşitliliğinin (size) artması ve protezin üzerine ve içine büyüme (ongrowth/ingrowth) tekniklerinin gelişmesi ile mükemmel femoral tespitler elde edilse de; geçmeyen uyluk ağrısı, stres kalkanı (stres shielding) gibi başka problemler ortaya çıkmaya başladı. Bu problemlerin aşılması için poroz kaplı anatomik protezler üretildi. Özellikle proksimal poroz kaplı, içe büyüme özellikli kobalt-krom protezlerle mükemmel biyolojik tespitler yapıldı. ${ }^{[7]}$

Çimentosuz femoral stem dizaynında konik incelen (tapered) sistemler önemli bir yer tutar. Bu dizaynda femoral komponent proksimal ve distalde posterior kortikal kemikle temastayken; orta bölümde (metafizo-diafizer bölgede) anterior korteks ile temastadır. Konik incelen femoral komponentler işte bu üç nokta tespit prensibiyle başlangıçta güçlü bir tespit sağlarlar. ${ }^{[8-10]}$ Erken dönemde elde edilen güçlü femoral tespitin uzun dönem sağkalımda önemli rolü olduğu aşikârdır. Bu dizayna eklenen içe veya üzerine büyüme özelliği ile de uzun dönemde başarılı tespit elde edilir. Ayrıca bu yöntemle uyluk ağrısı ve stres kalkanı oluşumu da azaltılmıştır. ${ }^{[11]}$

\section{Cerrahi teknik}

Cerrahi teknik ameliyat öncesi planlama ile başlar. Ameliyat öncesi planlama için gerçek bir anteroposterior pelvis ve tam yan kalça grafisine ihtiyaç vardır. Çekilen filmlerde pelvik eğim, femoral şekil
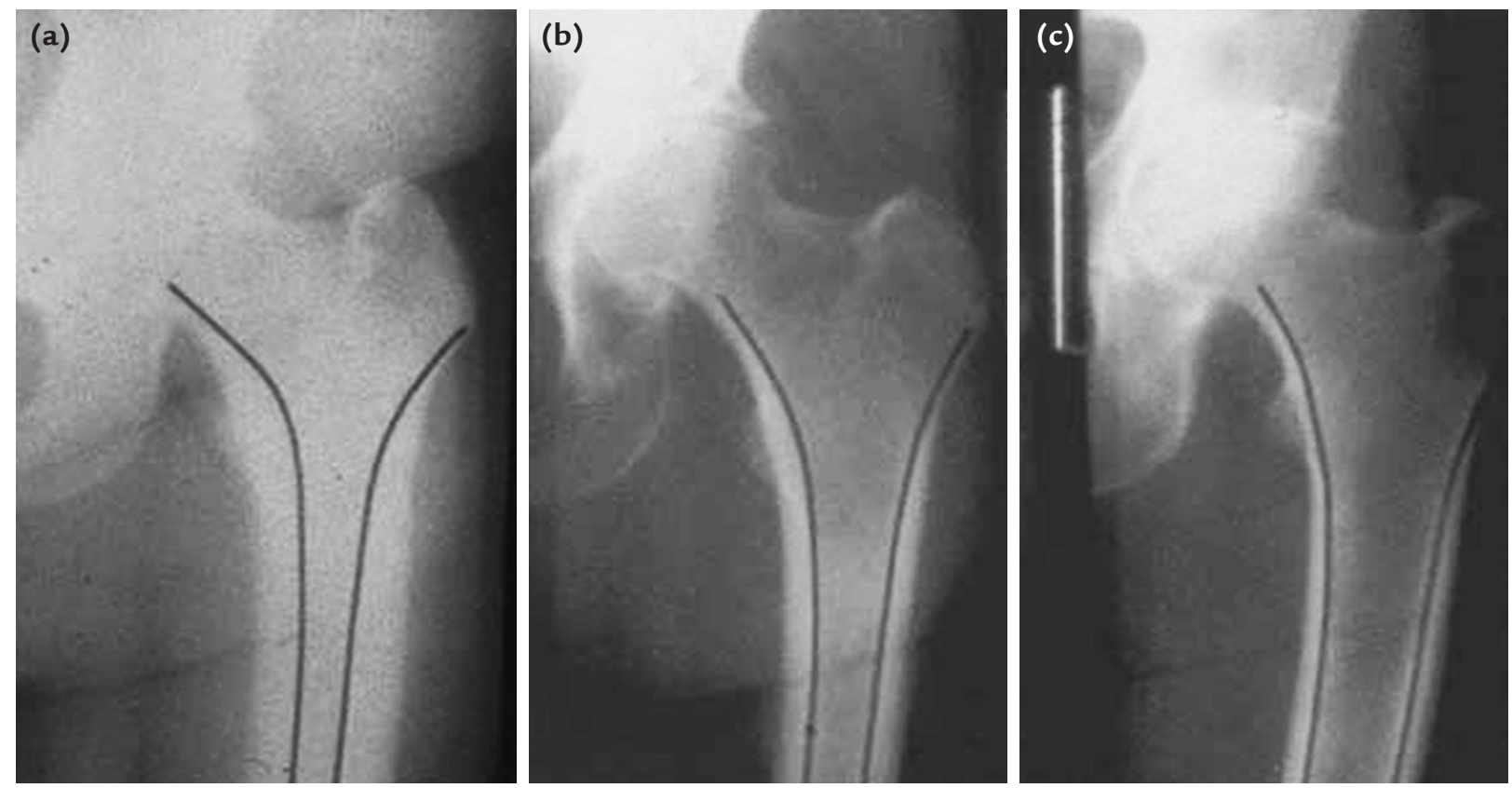

Şekil 1. Proksimal femur morfolojik sınıflama: (a) Dorr tip A, (b) Dorr tip B, (c) Dorr tip C. Dorr tip A ve B kalçalar çimentosuz femoral stemler için idealdir. 
bozuklukları (yanlış kaynama, deformiteler gibi) mutlaka değerlendirilmelidir. Femur boyun kesisi genellikle trokanter minörün $1 \mathrm{~cm}$ üzerinden yapılmakla beraber; varusta kalçalarda, antevert boyun açısı olan displastik kalçalarda daha distalden femur boyun kesisi yapmak gerekebilir. Benzer şekilde bacağı uzatmak için veya valgusta femur boyun açısı olanlarda daha proksimalden boyun kesisi yapılabilir. Kullanılan implant özellikleri bilinmeli, delici oyucu ve deneme protezlerinin gerçek protez boyutlarına göre değerlendirilmesine hakim olunmalıdır. Bacak eşitliğini sağlamak için kalça daha çıkarılmadan ameliyat içi ölçme kılavuz noktaları belirlenmeli ve işaretlenmelidir (Şekil 2).

Ameliyat sonrası meydana gelebilecek enfeksiyon harici belli başlı komplikasyonlar yumuşak doku dengesi bozukluğu, protez çıkığı, stress kalkanı oluşumu, uyluk ağrısı olarak sıralanabilir.

\section{Uyluk ağrısı}

Çimentosuz protezlerde, çimentolu protezlere göre daha fazla uyluk ağrısı görüldüğü kabul edilmektedir. Bununla beraber uygun seçilmiş protez tasarımı ve uygun yüzey alternatiflerinin kullanılmasıyla çimentosuz stemlerdeki uyluk ağrısının, çimentolu stemlerden farklı olmadı̆̆ını gösteren çalışmalar vardır. ${ }^{[1,2,7]}$ Silindirik distal tutunumlu protez dizaynlarında uyluk ağrısı sıkça görülmekte iken; konik incelen çimentosuz femoral komponentlerde daha az görülür. ${ }^{[12]}$ Altı ay ile bir yıl arasında süren ve sonrasında kaybolan bir ağrı şeklindedir. Her şeye rağmen vakaların çoğunda uyluk ağrısı semptomları dayanılabilirdir ve revizyon nedeni değildir. İki yılın üzerinde devam etmesi uyluk ağrısının diğer nedenlerini araştırmayı gerektirir.

\section{Stres kalkanı}

Femoral komponent ile temas ettiği kortikal kemik arasındaki stres dağııımı ilişkisi stres kalkanı oluşumunu belirler. Stres kalkanı oluşumunda hastanın kortikal kemik kalitesi, implant sertliği ve dizaynı önemli rol oynar. Şiddetli osteoporozu olan hastalarda stress kalkanı oluşumunun daha fazla olduğu gösterilmiştir. Distal tutulumlu protezlerde stresin implant üzerinden direk olarak distal kortikal kemiğe iletilmesi proksimal bölgede kemik mineral yoğunluğunda kayba neden olur. ${ }^{[13]}$ Benzer şekilde daha sert olan kobalt-krom protezler titanyum protezlere oranla daha fazla stres kalkanı oluşumuna neden olurlar. Özellikle $13.5 \mathrm{~mm}$ den daha kalın protezlerde stres kalkanının görülme sıklığının arttığı gösterilmiştir. Bununla beraber konik incelen titanyum protezlerde stresin proksimalden distale daha kademeli olarak dağılması stres kalkanı oluşumunu azaltmaktadır.

\section{Periprostetik kırık - yumuşak doku dengesi}

Total kalça proteziyle beraber periprostetik kırık görülme sıklığı \%0,1'dir. ${ }^{[14]}$ Periprostetik kırıklar proteze

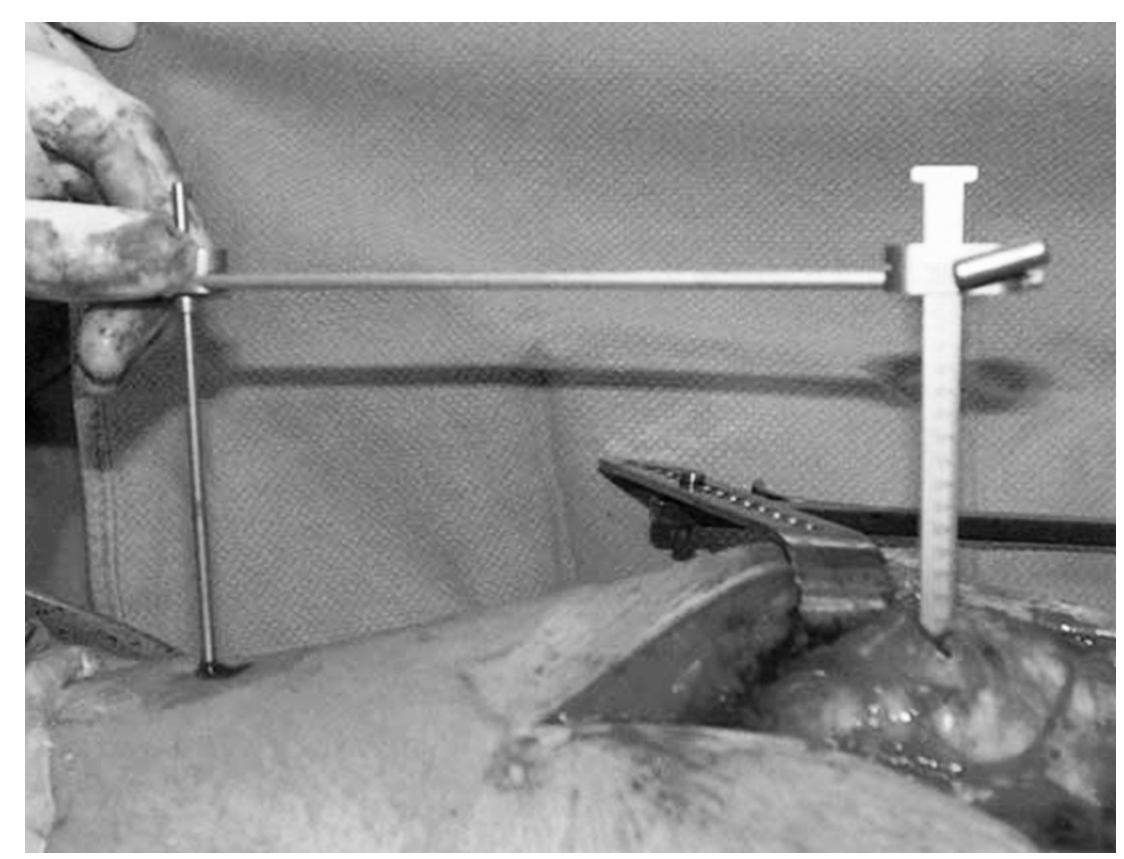

Şekil 2. Bacak eşitliğini sağlamak için kalça daha çıkarılmadan ameliyat içi ölçme kılavuz noktaları belirlenmeli ve işaretlenmelidir. 
olan ilişkilerine göre sınıflandırılırlar. Kırığa rağmen iyi tespit edilmiş bir protezde genellikle kabloyla tespite uygun plaklar ve yapısal allogreftler ile kırık tedavisi yapilır. Ama iyi tespit edilmiş protezlerde de, kırık nedeni ile gevşemiş protezlerde de eski protezin çıkartılıp kırık hattını geçen yeni bir protez koyulmasının daha iyi olacağını savunanlar vardır. ${ }^{[15,16]}$ Periprostetik kırıkların iyi tespit edilmiş bir protezde kronik gevşemeye bağlı ilerleyici endosteal incelme sonucu olabileceği de akıldan çıkarılmamalıdır. ${ }^{[17]}$

Aksamanın giderilmesi ve yardımcı yürüme cihazlarına ihtiyacın azaltılması için kalçanın abduktor adele gücü mutlaka düzenlenmelidir. Bu amaçla uygulanan protez ile femur başının rotasyon merkezi ve femoral ofset uygun olarak oluşturulabilmelidir. ${ }^{[18,19]}$ Yumuşak doku dengesinin sağlanması çıkığın önlenmesinin yanı sıra polietilene binen yük dağılımının düzeltilmesi dolayısıyla polietilen aşınmasının azaltılması için de gereklidir.

\section{ÇIMENTOLU FEMORAL KOMPONENT}

Çimentolu kalça protezi ilk kez 1960'larda John Charnley tarafindan uygulanmıştır. ${ }^{[20]} \mathrm{O}$ zamandan beri literatürde çimentolu stemlerin uzun dönem sonuçları ile ilgili birçok makale yayımlanmıştır, ne yazık ki bunlarda fikir birliği bulunmamaktadır. Sonuçların tutarsızlığının sebebi olarak hasta seçimindeki farklıIıklar, farklı femoral komponent kullanımları, implant teknikleri, çimentolama teknikleri ve hatta çimento çeşitleri sayılabilir. ${ }^{[21]}$ Ayrıca başarısızlı̆̆ın tanımı da farklı olabilmektedir. Genel olarak ağrı, osteoliz, revizyon gereksinimi ve radyolojik gevşeme başarısızlığı gösteren bulgulardır. Bugün aseptik gevşeme olarak tanımladığımız femoral stemdeki gevşeme durumu daha önceleri çimento yetmezliği, ayrışması olarak bilinmekteydi.

\section{Protez çimento ilişkisi}

Çimentonun asıl işlevi implantın primer stabilitesini sağlarken kalça ekleminden metal protez yoluyla gelen yükleri eşit olarak endosteal kemiğe iletmektir. İdeal protez yeterli çimento mantosuyla çevrelenmiş kemiğe uygun boyuttaki protezdir. Protezin yüzey pürüzlülügün artması implant ve çimento arasındaki erken dönem stabiliteyi artırıcı etkiye sahiptir. Burada çimento bir sıva gibi protez üzerindeki oyuk ve tepelerin üzerini örter. Ancak bu tip sementli protez sonuçları genellikle geç dönemde başarısız olmaktadır.

\section{Kemik çimento ilişkisi}

Kemik çimento ara yüzeyini uygun hale getirmek için femoral kanalın uygun şekilde hazırlanması şarttır. Kansellöz kemiğin stabil tabakasına kadar kemik örtüsü oyulmalıdır. Oyucunun nötral pozisyonu ve uygun anteversiyonu protez kanal uyumunun üst seviyede olmasını sağlar. Burada dikkat edilecek özellik motorlu oyucuların, çimentonun kemiğin iç taraflarına nüfus etmesini engelleyecek kadar pürüzsüz yüzey oluşturma eğiliminde olmasıdır. Gerekirse son oyucudan sonra küret yardımıyla endosteal yüzey pürüzlendirilmelidir. Kanal içindeki kemik parçaları, debrisler ve kan iyi bir çimentolama tekniği için temizlenmelidir. Çimentonun tabanca ile basınçlı uygulanması, tıkaç yardımıyla meduller kanalın sınırlandırılması, çimentodan sonra protezin yerleştirmesi sırasında ortaya çıkan ek basınç etkisi çimentonun trabeküler kemiğe iyice nüfus etmesini sağlar.

Çimentolama tekniklerindeki gelişmeler daha stabil ve merkezi protez uygulamalarını mümkün kılmıştır. Birinci jenerasyon çimentolamada herhangi bir alet kullanmaksızın tıkaç konulmamış femoral kanala parmak yardımıyla çimento yerleştirilir. Standart bir tabaka sağlanması zordur. İkinci jenerasyon çimentolamada basınçlı yıkama ile kanal temizlenir. İntramedullar tıkaç uygulanarak kanal sınırlandırılır. Çimento distalden proksimale tabanca yardımıyla doldurulur. Üçüncü jenerasyon çimentolamada çimento vakum altında karıştırılarak hazırlanır. Çimento basınç ile kanala verilir. Dördüncü jenerasyon çimentolamada ise protezin doğru yönelimi için proksimal ve distal ortalayıcı (centralizer) kullanılır. ${ }^{[22]}$ Ortalayıcılar oldukça önemlidir. Noble ve ark. ${ }^{[23]}$ yaptıkları çalışmada, ortalayıcı kullanmadan, sadece distal ortalayıcı kullanarak ve proksimal ve distal ortalayıcıyı beraber kullanarak yapılan protezlerin yönelimlerini araştırmışlardır. Buna göre ortalayıcı kullanmadan yapılan protezlerde \%49 distal, \%35 proksimal yanlış yönelim; sadece distal ortalayıcı kullanılan protezlerde \%3 distal, \%19 proksimal yanlış yönelim ortaya çıkmışken her iki ortalayıcının kullanılması ile hiç yanlış yönelim saptanmamıştır. Birinci jenerasyon çimentolamada ulaşılan kanal içi çimento basıncı $10 \mathrm{lb} /$ in $^{2}$ civarındayken, kanal içi tıkaç ve distalden proksimale dolum tekniği kullanılarak ölçülen çimento basıncının $35-70 \mathrm{lb} /$ in $^{2}$ olduğu görülmüştür. ${ }^{[23]}$ Ayrıca parmakla çimentolama tekniğinde çimento içinde biriken kan ve yabancı cisim partikülleri çimentonun polimerizasyonunu zayıflatmaktadır.

\section{Çimentolama zamanlaması}

Çimentonun zamanında uygulanması teknik olarak önemlidir. Çimentonun daha sıvı şekliyle uygulanması tesir ettiği yüzeyin (protez veya endosteal) daha iç tabakalarına ilerlemesine neden olur. Özellikle pürüzlü yüzeyli protez kullanılıyorsa çimentonun erken uygulanmasının, çimentonun proteze daha fazla tutunmasına neden olduğu gösterilmiştir. Bu da erken dönemde stabilizasyonu arttırmaktadır. Bununla beraber parlak yüzeyli protez kullanılıyorsa çimento 
uygulama zamanlamasının stabilite yönünden önemi yoktur. Hatta protezin yönelim ve oryantasyonunun daha katı çimento ile daha kolay elde edilebileceği akılda tutulmalıdır. ${ }^{[24]}$

\section{Çimentonun katılaşması}

Çimento sertleşmeden önce protezin en uygun yönelimde yerleştirildiğinden emin olunmalıdır. Protezin iyi pozisyonda yerleştirilmesi oluşabilecek varus-valgus pozisyonunun önüne geçmesinin yanında, uygun kalınlıkta çimento mantolanması için de gereklidir. ${ }^{[25]}$ Femoral komponentin kanal içinde santralizasyonu sayesinde çimento tabakası eşit şekilde dağılmakta, tabakanın ince olması veya tabakada defekt olması engellenmektedir. Çimento dayanıklılığı için en önemli faktörün tabaka kalınlığı olduğu bulunmuştur. ${ }^{[26,27]}$ Uygun çimentolanmış bir protezde, protezi çepeçevre saran en az 2 mm'lik çimento tabakası bulunmalıdır. ${ }^{[28]}$ Benzer şekilde bu çimento tabakası protezin en distalini de en az $2 \mathrm{~cm}$ geçmelidir.

Çimento sıvı halden katı hale ekzotermik bir reaksiyon ile gelir. Burada meydana gelen Isı protez ve kemik boyunca yayılır. Bu ısınma sırasında çimentonun hacminde sıvı haline göre yaklaşık \%3-5'lik bir artma meydana gelir. Bu durum da çimentonun etkisini güçlendirmektedir.

\section{Biyomekanik}

Çimentolu sistemin tespit gücü; çimento protez ara yüzü ve çimento kemik ara yüzünün tespit gücüne bağlıdır. Gevşeme ilk olarak çimento-protez ara yüzünde meydana gelir. ${ }^{[29]}$ Çimentolu protezlerde erken gevşemeden sorumlu birçok faktör vardır. Çimento mantosu üzerindeki artmış mekanik stres bunlardan biridir. Proksimal bölgedeki kemik rezorpsiyonu, proksimal çimento tabakasındaki mekanik stresi arttırır, mikroharekette artma olur ve çimento uygulamasında erken başarısızlık meydana gelir. Mikrohareketler ile açığa çıkan debrisler ve onlara karşı oluşan yabancı cisim reaksiyonu da gevşemeyi arttırır.

Aslında protez çimento ara yüzey stabilitesi stem özelliklerine ve cerrahi tekniğe bağlıdır. Özellikle pürüzsüz parlak yüzeyli, yakalıksız sistemlerde bir miktar çökme (subsidence) her zaman beklenir. Bu gevşemeden ziyade protezin sabitlendiği anlamına gelmelidir. Protezin çökmesi (subsidence) bazı protez yüzeylerinde (parlak) ve dizaynlarda (force closed) çimentonun genişlemesine bağlı olarak stabiliteyi arttırırken; shape closed dizaynlarda gevşemenin belirtisi olarak kabul edilir. Özellikle ilk iki yılda 1,2 mm'nin üzerindeki çökmeler yüksek revizyon oranlarıla beraberdir. ${ }^{[29]}$ Bunun yanında mat sistemlerin parlak sistemlere göre erken dönemde daha fazla dışa çekme (pullout) gücüne sahip olduğu aşikârdır. ${ }^{[30]}$ Aslında literatürde hangi yüzey kaplamalı protezin daha iyi sonuçları olduğu konusu hala tartışmalıdır. ${ }^{[21,31,32]}$

Protez özellikleri de gevşemede önemlidir. Titanyum gibi elastik implantlar çimento üzerine artmış stres transferine, artmış mikroharekete, dolayısıyla korozyon ve osteolize neden olurlar. ${ }^{[21,33]}$ Kobalt-krom gibi daha sert implantlar ise stresin transferine izin vermezler fakat kemik resorpsiyonuna neden olarak gevşemeye yol açabilirler. ${ }^{[34,35]}$ ideal implant sertliği kobaltkrom ile titanyum arasında bir yerde bulunmaktadır. Benzer şekilde çimentolu protezlerde ofsetin artması çimento yoluyla iletilen streste artmaya sebep olur. Bu yüzden ameliyat öncesi ofset değerlendirmesi iyi yapılmalıdır. Çimentolu protezlerde stemin boyu 100-110 mm'den kısa ise daha yüksek gevşeme oranları bildirilmektedir. ${ }^{[21]}$

Gevşemenin radyolojik değerlendirmesi Gruen ve ark.'larının tarif ettiği şekilde femuru 7 bölgeye ayırarak yapılır. Harris ve ark. ${ }^{[36]}$ çimento protez arayüzünün değerlendirilmesinde 3 farklı senaryo tarif etmişlerdir. Buna göre çökme (subsidence), pedestal oluşumu, çimento kırılması, protezin \%100'ünde meydana gelen radyolusen alan kesin gevşemeyi; \%50-99 arasında radyolusen alan yüksek muhtemel gevşemeyi; ve \%50'nin altında protez çevresi radyolusen alan gevşeme ihtimali olduğunu göstermektedir.

Çimentolu protezleri genel olarak değerlendirdiğimizde başarıda hasta seçiminin de önemli olduğunu görürüz. Genç hastalar ile yapılan birçok başarılı çalışma mevcutken çok daha fazla sayıda başarılı çalışma yaşlı hastalar ile bildirilmiştir. ${ }^{[37-39]}$ Çimentolu protezin başarısında asıl olan çimentolama tekniğidir. Yeterli kemik mantosu, uygun yönelimde protez ve çimento defektlerinin en aza indirildiği uygulama başarıyı getirir. İmplant seçimi de başarıyı etkileyen bir faktördür. Birçok implant piyasada mevcutken, başarılı olanların ortak özellikleri; partikül ve debris oluşumunu azaltmak için parlak yüzeyli ve yuvarlak köşeli , lokal çimento streslerini önlemek için inceltilmiş geometride ve kısmen sert materyalden (kobalt-krom, paslanmaz çelik gibi) yapılmış olmalarıdır.

\section{KAYNAKLAR}

1. Bourne RB, Rorabeck CH, Laupacis A, Tugwell P, Wong C, Bullas $R$. Total hip replacement. The case for non-cemented femoral fixation because of age. Can J Surg 1995;38 Suppl $1:$ S61-6.

2. Rorabeck $\mathrm{CH}$, Bourna RB, Laupacis A, Feeny D, Wong C, Tugwell P, Leslie K, Bullas R. A double blind study of 250 cases comparing cemented with cementless total hip arthroplasty. Cost-effectiveness and its impact on health related quality of life. Clin Orthop Relat Res 1994;(298):156-64. 
3. Laupacis A, Bourne R, Rorabeck C, Feeny D, Tugwell P, Wong C. Comparison of total hip arthroplasty performed with and without cement: a randomized trial. J Bone Joint Surg Am 2002;84-A(10):1823-8.

4. Dorr LC, Faugere MC, Mackel AM, Gruen TA, Bognar B, Malluche $\mathrm{HH}$. Structural and cellular assessment of bone quality of proximal femur. Bone 1993;14(3):231-42.

5. Dalury DF, Kelley TC, Adams MJ. Modern proximally tapered uncemented stems can be safely used in Dorr type $C$ femoral bone. J Arthroplasty 2012;27(6):1014-8. CrossRef

6. Kelly SJ, Robbins CE, Bierbaum BE, Bono JV, Ward DM. Use of a hydroxyapatite-coated stem in patients with Dorr Type C femoral bone. Clin Orthop Relat Res 2007;(465):112-6.

7. Kawamura H, Dunbar MJ, Murray P, Bourne RB, Rorabeck $\mathrm{CH}$. The porous coated anatomic total hip replacement: a ten to fourteen year follow-up of a cementless total hip arthroplasty. J Bone Joint Surg Am 2001;83-A(9):1333-8.

8. Schmalzried TP, Jasty M, Harris WH. Periprosthetic bone loss in total hip arthroplasty. Polyethylene wear debris and the concept of the effective joint space. J Bone Joint Surg Am 1992;74(6):849-63

9. Bourne RB, Rorabeck CH, Patterson JJ, Guerin J. Tapered titanium cementless total hip replacements: a 10- to 13-year followup study. Clin Orthop Relat Res 2001;(393):112-20.

10. Delauncy C, Kapandji Al. 10-year survival of Zweymüller total prostheses in primary uncemented arthroplasty of the hip. Rev Chir Orthop Reparatrice Appar Mot 1998;84(5):421-32.

11. Campbell AC, Rorabeck CH, Bourne BB, Chess D, Nott L. Thigh pain after cementless hip arthroplasty. Annoyance or ill omen. J Bone Joint Surg Br 1992;74(1):63-6.

12. Engh CA Jr, Culpepper WJ 2nd, Engh CA. Long-term results of use of the anatomic medullary locking prosthesis in total hip arthroplasty. J Bone Joint Surg Am 1997;79(2):177-84.

13. Gibbons CE, Davies AJ, Amis AA, Olearnik H, Parker BC, Scott JE. Periprosthetic bone mineral density changes with femoral components of differing design philosophy. Int Orthop 2001;25(2):89-92.

14. Mont MA, Maar DC. Fractures of the ipsilateral femur after hip arthroplasty. A statistical analysis of outcome based on 487 patients. J Arthroplasty 1994;9(5):511-9.

15. Fink B, Grossmann A, Singer J. Hip revision arthroplasty in periprosthetic fractures of vancouver type B2 and B3. J Orthop Trauma 2012;26(4):206-11. CrossRef

16. Park SK, Kim YG, Kim SY. Treatment of periprosthetic femoral fractures in hip arthroplasty. Clin Orthop Surg 2011;3(2):101-6. CrossRef

17. Johannson JE, McBroom R, Barrington TW, Hunter GA. Fracture of the ipsilateral femur in patients with total hip replacement. J Bone Joint Surg Am 1981;63(9):1435-42.

18. Davey JR, O'Connor DO, Burke DW, Harris HW. Femoral component offset. Its effect on strain in bone-cement. J Arthroplasty 1993;8(1):23-6.

19. McGrory BJ, Morrey BF, Cahalan TD, An KN, Cabanela ME. Effect of femoral offset on range of motion and abductor muscle strength after total hip arthroplasty. J Bone Joint Surg Br 1995;77(6):865-9.

20. Charnley J. Anchorage of the femoral head prosthesis of the shaft of the femur. J Bone Joint Surg Br 1960;42-B:28-30.

21. Barrack RL. Early failure of modern cemented stems. J Arthroplasty 2000;15(8):1036-50.
22. Maloney W, Kang M, Hartford J, Total hip arthroplasty / Primary total hip arthroplasty / The cemented femoral component. Callaghan JJ, Rosenberg AG, Rubash HE, editors. The Adult Hip. 2nd ed. Philadelphia: Lippincott Williams \& Wilkins; 2007. p. 917-40.

23. Noble PC, Collier MB, Maltry JA, Kamaric E, Tullos HS. Pressurization and centralization enhance the quality and reproducibility of cement mantles. Clin Orthop Relat Res 1998;(355):77-89.

24. Shepard MF, Kabo JM, Lieberman JR. The Frank Stinchfield Award. Influence of cement technique on interface strength of femoral components. Clin Orthop Relat Res 2000;(381):26-35.

25. Köster G, Willert HG, Ernstberger T, Köhler HP. Centralization of the femoral component in cemented hip arthroplasty using guided stem insertion. Arch Orthop Trauma Surg 1998;117(8):425-9.

26. Breusch SJ, Lukoschek M, Kreutzer J, Brocai D, Gruen TA. Depency of cement mantle thickness on femoral stem design and centralizer. J Arthroplasty 2001;16(5):648-57.

27. Estok DM 2nd, Harris WH. A stem design chance to reduce peak cement strains at the tip of a cemented total hip arthroplasty. J Arthroplasty 2000;15(5):584-9.

28. Goldberg BA, al-Habbal G, Noble PC, Paravic M, Liebs TR, Tullos HS. Proximal and distal femoral centralizers in modern cemented hip arthroplasty. Clin Orthop Relat Res 1998;(349):163-73.

29. Alfaro-Adrián J, Gill HS, Murray DW. Cement migration after THR. A comparison of charnley elite and exeter femoral stems using RSA. J Bone Joint Surg Br 1999;81(1):130-4.

30. Huiskes R, Verdonschot N, Nivbrant B. Migration, stem shape, and surface finish in cemented total hip arthroplasty. Clin Orthop Relat Res 1998;(355):103-12.

31. Charnley J. Low Friction Arthroplasty of the Hip: Theory and Practice. New York: Springer-Verlag; 1979.

32. Middleton RG, Howie DW, Costi K, Sharpe P. Effects of design changes on cemented tapered femoral stem fixation. Clin Orthop Relat Res 1998;(355):47-56.

33. Schöll E, Eggli S, Ganz R. Osteolysis in cemented titanium alloy hip prosthesis. J Arthroplasty 2000;15(5):570-5.

34. Lewis JL, Askew MJ, Wixson RL, Kramer GM, Tarr RR. The influence of prosthetic stem stiffness and of a calcar collar on stresses in the proximal end of the femur with a cemented femoral component. J Bone Joint Surg Am 1984;66(2):280-6.

36. Wan Z, Dorr LD, Woodsome T, Ranawat A, Song M. Effect of stem stiffness and bone stiffness on bone remodeling in cemented total hip replacement. J Arthroplasty 1999;14(2):149-58.

36. Harris $\mathrm{WH}$. The case for cementing all femoral components in total hip replacement. Can J Surg 1995;38 Suppl 1:S55-60.

37. Barrack RL, Mulroy RD Jr, Harris WH. Improved cementing techniques and femoral component loosening in young patients with hip arthroplasty. A 12-year radiographic review. J Bone Joint Surg Br 1992;74(3):385-9.

38. Ballard WT, Callaghan JJ, Sullivan PM, Johnston RC. The results of improved cementing techniques for total hip arthroplasty in patients less than fifty years old. A ten-year follow-up study. J Bone Joint Surg Am 1994;76(7):959-64.

39. Ogino D, Kawaji $H$, Konttinen $L$, Lehto $M$, Rantanen $P$, Malmivaara A, Konttinen YT, Salo J. Total hip replacement in patients eighty years of age and older. J Bone Joint Surg Am 2008;90(9):1884-90. CrossRef 